can e first affected on the 23rd. It appeared that he slept with lis broth $r$, and was engaged with him in the same employn.ent. The appearance and situation of the eruption was exactly the same as in the fo mer case; in this case, however, there $\mathbf{w}$ เs great heat, but no $i$ :ching.

Treatment. - In this case I used the nitrate in solution, ten grains to one ounce of water. He was under treatment five weeks.

J. E- a a a twenty-three, another brother, came under treatment on April 18th. He had not slept with his brothers, but worked on the same farm; and upon the occasion of his brother's illness, took his place in attending to the horses. In his case the eraption never appeared in any situation but on the left cheek, over nearly the whole of which it extended.

Treatment. - The solid nitrate was used only twice, when the disease entirely subsided.

The disease appears to commence in small elevated red pimp'es, with a white speck in the centre; these quickly enlarge, dividing into a distinct centre and circumference, raised considerably above the level of the surrounding skin. The centre is of a deep-red colour, with small elevations scattered all over its surface, and surrounded by two distinct rings: the inner formed of thin white scales; the outer being apparently a raised ring of inflamed cuticle, of a bright-red colour, which gradually becomes lost in that of the surrounding skin.

Remarks. - I think I am justified in coming to the conclusion that the disease, whatever it is, was communicated to my patients from the diseased horse; for the last patient never slept with either of his brothers, and, in fact, did not live in the same house; moreover, up to the time he took charge of the diseased horse he remained perfectly free from the complaint, but upon doing so became at once affected. What the affection is I will not venture to say, although I am inclined to consider it as somewhat related to some form of lepra. I do not find it mentioned by any author on skin diseases, that farcy can produce any other form of disease than one of its own kind; and yet in none of my patients were the lymphatics affected, nor was there any very great amount of constitutional disturbance.

The nitrate of silver appears at once to exert a clirect effect in cuttingr short the disease.

Yovember: 1858

\section{REPORT OF A}

\section{CASE OF CANCROID TUBERCULOSIS OF FOURTEEN YEARS' STANDING,}

\section{SUCCESSFULLY TREATED BY ACID NITRATE} OF MERCURY.

By H. WARNER BUBB, Esq., M.R.C.S. \&c., Welwyn.

H. C. A- aged seventy-two, an hotel-keeper, of temperate habits and good general health, first perceived, fourteen years ago, a small pimple on the left side of the upper lip. It soon increased in size, began to ulcerate, and became very painful and irritable. He was under the care of a surgeon for some time without relief, and was unsuccessfully treated by other surgeons; at length, after being several times threatened with the "knife," he consulted the late Mr. Aston Key, who applied chloride of zinc to the ulcer. This treatment appeared at first to be successful; but after a time the affection became as bad as ever.

I saw him for the first time in March. On examination, I found an ovoid-shaped and very cancerous-looking ulcer, with jagrged edges and somewhat hardened base, extending from the angle of the month to the left side of the nose. There was no discharge. He complained of pains "shooting upwards to the eye and downwards to the throat, and great itching." I removed the scab with which the ulcer was thickly covered, and touched the surface freely with nitrate of silver, and continued this treatment until three months ago, with little or no result. I then hall recourse to the acid nitrate of mercury, which I applied weekly. The tffect has been extraordinary. The ulcer is now quite skinned over, and appears to be cured.

Oetober, 1858 .

dpporntaent.-Mr. George Augustus Ibbetson has been appointed Dental Surgeon to University College Hospital, and Lecturer on Dental Surgery at University college Hospital.

\section{a}

OF THE PRACTICE OF

\section{MEDICINE AND SURGERY \\ IY THE}

HOSPITALS OF LONDON.

Nulla est alia pro certo noscendi via, nisi quam plurimas et morborum et dissectionum historias, tam aliorum proprias, collectas habere et inter se comparare,-MorgagNi. De Sed.et Caus. Jiorb.lib.14. Procmium,

\section{ST. MARY'S HOSPITAL.}

STRICTURE OF THE URETHRA, WITH SWELIING OF THE SCROTUM ; EXTERNAL DIVISION ; CURE.

(Under the care of Mr. Coolsox.)

WIrHoUT entering at length into the various questions connected with the perineal section, we may state, as indeed the following case shows, that the operation is occasionally an extremely simple one, and is sometimes attended with early success. A grooved director is passed through the stricture, which is divided on the directo"; the wound heals in a few weeks, and the patient is apparently cured of a distressing malady. We say " apparently," because a certain period must elapse before the result of the operation can be determined. The dangers of this operation may have been exaggerated, as Mr. Coulson, we understand, has lost only one patient out of a considerable number operated on by him. The cause of death was pyæmia; and it is a fact well worthy of notice that in nearly all the fatal cases which have occurred the patients were cut off by the same fatal complication. Still while the surgeon has at command the " guides and tubes" invented by Mr. Thomas Wakley-instruments which have now been used in so many cases with safety and success, and without proving fatal in a single instance, it certainly is questionable whether, in every case where a grooved staff can be passed through the stricture, the tubes shonld not be employed before the far more serious operation of the perineal section is attempted. Assuredly the triumph of surgery arises from healing, and not from making wounds.

Richard G-_-, aged thirty-six, labourer, married, was admitted on April 9th, 1558, with stricture of the urethra and with swelled testicle. The scrotum was found to be much swollen, hard at the lower part, and painful. There was a fistulous opening in the perinæum, about three-quarters of an inch long, through which the urine dribbled. The patient could pass his nrine, but in a very small stream. Abont twelve months ago he strained himself whilst carrying a sack of lime, and had swelling of the scrotum, and subsequently an abscess in the perinæum. On the 3rd of A pril last he again strained himself whilst pushing a railway truck, which, he states, was the cause of the swelling in the scrotum.

April 10th.-Mr. Coulson tried to pass a No. 4 catheter, but could not do so.

14th. - The patient being placed und $r$ the influence of chloroform, Mr. Coulson succeeded in passing a No. 1 Syme's staff into the bladder; be then molle an incision in the neringum about two inches long, cut down upon the staff, and divided the stricture. He then passed a director from the wound along the groove of the staff into the bladder; the staff was now withdrawn, and a No. 8 catheter was passed.

17th. - The patient has been doing well since the operation. The catheter (which has caused but little irritation) was re. moved to-day.

19th. - Did not sleep well. Complains of pain in the right lower extremity, from the plantar surface of the foot to the ilium. The urine flows through the incision; he does not pass any through the urethra. Has a good appetite, and but little pain in the seat of the incision.

20 th. - Had rigors last night, which lasted for about an hour, succeeded by a hot and sweating stage.

21st. - Rigors again this morning at two o'clock; feels weak; has no appetite; does not complain of pain in any part of the body, nor is there any soreness where the incision was made. The urine still flows entirely through the wound. 
22nd.-Better. Has had no more rigors since yesterday morning.

23rd.-Considerably better. Has a very good appetite; has not had any more rigors. A No. 6 catheter was passed yesterday, and kept in for six hours. The urine now comes partly through the urethra.

27 th.-Going on well. The urine is passed partly through the urethra and partly through the incision.

28th. - The greater part of the urine was passed through the urethra to-day. A catheter is to be introduced once a week.

May 8th.-The wound in the perincum is healed, and a No. 8 catheter can be passed with ease.

\section{UNIVERSITY COLLEGE HOSPITAL.}

CARIES OF THE TARSUS; SYME'S AMPUTATION AT TFE ANKLE-JOINT ; RECOVERY, WITH A GOOD STUMP.

\section{(Under the care of Mr. Marshall.)}

OUR readers will recollect the three examples of Pirogoft's operation of amputation at the ankle-joint which we recorded in our "Mirror" of Oat. 2nd (p. 350). We then promised to bring forward some cases in which Syme's amputation was resorted to, and we now give the details of two. Without going into the history of this operation, now so well known and extensively practised, we may refer to the condition of the stump which is obtained. In the greater number of the cases which have come under our notice in hospital practice, the resulting stump has been very good, the integument of the heel becoming firmly joined to the lower end of the tibia, and affording support by means of the part which nature intended the body to rest upon. The patients, when other circumstances were favourable, have moved about with comfort and ease, being free from pain, aching, and tenderness in the stump. We have, it is true, seen some exceptions to this satisfactory result, such as a painful stump some two years after the operation, or retraction of the heel; but the inconveniences which have arisen were such as would be likely to occur if any other operation had been performed, and depended in great measure on the peculiar constitution of the patient.

A well-formed, rounded stump, with a soft cushion to rest upon, is generally observed, good engravings of which are to be seen in the standard surgical works of the day. Although influenced in favour of Pirogoff's operation as we have seen it performed, time has yet to show whether the portion of the os calcis allowed to remain will prove an advantage, or will produce an aching and painful sensation. We much fear the latter. The advantage of that surgeon's operation is the celerity with which it can be performed, but this is by no means the chief consideration with a conscientious surgeon.

We deem it unnecessary to describe the steps of Mr. Syme's operation; they are already well known. In the following case, however, a slight modification was attempted of the lateral incision, as introduced by Mr. Quain, which consists, after the first incision is made from malleolus to malleolus under the os calcis, of a second straight one at right angles with the first, extending to the back part of the heel on the outer side of the foot, a little above and parallel with its outer margin-between, therefore, the point of the outer malleolus and the margin of the foot. Mr. Quain considers this plan facilitates the dissection from the os calcis, hastens the operation, and prevents the collection of pus.

The stump in Mr. Marshall's patient was exceedingly good, better than was ever anticipated from the diathesis present, as mentioned in the history of the case, the notes of which were furnished us by Mr. John S. Wilkinson, house-surgeon to the hospital.

Anne G- aged thirty-four, admitted on the 30th of July. She is slim, tuberculous-looking, and one of a delicate family. She has lost two sisters, one from phthisis, the other from acute rheumatism. Her occupation is superintendent of an envelope manufactory, which requires a good deal of morement on the feet. When young, she had an abscess in the neck. She has always had a slight cough. She dates her present illness six years since (1852), from an accident in slipping down stairs on her heel. After this, there was a continual pain in the left heel. Subsequently, on three successive occasions, at intervals in the years 1854, 1856, and 1857, after the formation of 524 abscesses about the os calcis, which, when opened, were found to lead down to the bone, Mir. Marshall removed portions of diseased bone. On the last two occasions, the os calcis was gouged freely out; and finally, granulations failing to take place, a large cavity existed in it. The resulting sinus discharged an oily, ill-conditioned pus, and the disease extended itself to the contiguous bones. As her constitution became impaired, it was deemed advisable to remove the foot.

Angust 11th. -Syme's operation, with Mr. Quain's modifica. tion, was performed. There was but little bleeding from the flap immediately after the operation. On dressing it a few hours after, there was general oozing from the surface. The flaps were brought together by three sutures, and waterdressings applied. Took a night-draught of tincture of opium (fifteen minims).

12th. - Passed a bad night; was sick many times; the stump is irritable and painful; the flaps are puffed ont, and a serobloody discharge escapes from the wound.

14th. - Stump irritable; the edges and angles of the incision on the onter side are purplish, and sensation, although evident, is yet obtuse. Treated wi h water-dressings.

16th. -Wound healing internally; externally, sloughs are separating. A strip of plaster supports the flap, and a poultice is applied.

18th. - The patient feels better; the sloughs have separated; flap well drawn down, and brought over the ends of the bones by long strips of plaster; wound dressed with sulphate-of-zine lotion.

22nd. - The ends of the bones and the wound granulate freely; the patient feels pretty well; appetite good.

Sept. 6 th. - Has gone on improving; the wound is healing; there are a few small sinuses, but they do not lead to the bone; the patient sits up, and feels much stronger.

1sth. - Patient much improved; stump all but healed, only a few small sinuses remaining; no bone exposed. The patient was discharged.

Nov. 4th. - Sinuses all closed, and general health re-esta. blished. The stump is good, and she boars pressure upon it without any inconvenience.

\section{ROYAL FREE HOSPITAL.}

EXTENSIVE CARIES OF THE TARSUS IN A WOMAN AGED SIXTY-FOUR; SYME'S OPERATION AT THE ANKLE-JOINT; RECOVERY, WITH A GOOD STUMP.

(Under the care of Mr. A. MARsDEN.)

Is the subjoined instance of Syme's amputation at the anklejoint, legitimately carried out, a very good stump was obtained, with a firm cushion to rest upon. Indeed, considering the patient's age, sixty-four years, (probably the oldest patient upon whom we have seen this operation performed,) such an excellent recovery, with a most useful stump, is somewhat surprising. The os calcis generally was affected with what $\mathrm{Mr}$. Gant describes as fatty disintegration of its cancellated structure, with free oil floating about. This rendered the bone so soft, that it broke in two pieces during removal.

For the notes of the following case we are indebted to $\mathrm{Mr}$. J. J. McGregor, house-surgeon to the hospital :-

Mrs. E. K-, a native of Ireland, aged sixty-four years, was admitted as an in-patient on the $8 \mathrm{th}$ of $\mathrm{July}$, 1858, with extensive caries of the left tarsus. Her appearance, on admis. sion, was indicative of extreme debility, she having suffered for upwards of seven years from severe pain, and lately a profuse discharge of purulent matter from the diseased part. She states that she first perceived, several years ago, what she called a "white swelling," which involved the whole of the foot and ankle; pain of an intense character shortly followed, espe. cially towards night, obliging her to keep to her bed. She called in various medical men, who tried numerous palliative measures, without any apparent relief to her symptoms.

On the Sth of July she applied to Mr. A. Miarsden, who admitted her at once. Although her health was very indifferent, still, being of opinion that early operative interference could alone save her life, and the patient herself being anxious to have anything done that would relieve her sufferings, he determined to operate upon her. Accordingly, after putting her on generous diet, on the 12 th-four days after admission-amputation of the foot was performed, after the manner of Mr. Syme. An excellent covering for the stump was obtained from the thick skin surrounding the heel, after sawing off the 